\title{
Mathematical Calculations of the Mass Transport of Radionuclides in the Water Flow of the River Yenisei, in the Impact Zone of the Mining and Chemical Combine
}

\author{
Lydia Bondareva $^{1,2^{*}}$, Natalya Fedorova ${ }^{1}$, Valerii Rakitskii ${ }^{1}$ \\ ${ }^{1}$ Federal Scientific Center of the Hygiene named after F.F. Erisman, Mitischi, Moscow region, Russia \\ ${ }^{2}$ Siberian Federal University, Krasnoyarsk, Russia \\ Email: lydiabondareva@gmail.com
}

\begin{abstract}
The data of monitoring the radiation and chemical situation in the middle reach of the Yenisei River have been included in mathematical calculations of the mass transport artificial radionuclides. Now we have the calculation algorithm for the mass transports artificial radionuclides in the river flow, including the suspended and bottom sediment dynamics, which can be used to simile river systems. The calculations showed that the concentration of the lightest fraction of the water on the current site remains virtually unchanged and those concentrations of suspended sediment decreases for heavier fractions decrease and, consequently, decreased the level of contamination. Our field data indicated an increase in the concentration of coarse fraction, which was associated not only with the resuspension-deposition, as well as with the coagulation of suspended solids.
\end{abstract}

Keywords: Artificial radionuclides, Yenisei River, mass transfer, water suspension, mathematical calculations

\section{Introduction}

The Yenisei flowing northwards across central Siberia into the Kara Sea is one of the world's largest rivers. The total length of the river is about $4000 \mathrm{~km}$ and the catchment area is $2.6 \cdot 10^{6} \mathrm{~km}^{2}$, covered mainly by forests $(49 \%)$, grasslands $(18 \%)$, shrubs $(15 \%)$, croplands $(13 \%)$ and wetland $(3 \%)[1]$. All major tributaries of the Yenisei, Angara (average water discharge near its mouth about $\left.5100 \mathrm{~m}^{3} \cdot \mathrm{s}^{-1}\right)$, Podkamennaya Tunguska $\left(1750 \mathrm{~m}^{3} \cdot \mathrm{s}^{-1}\right)$, Nizhnaya Tunguska $\left(3680 \mathrm{~m}^{3} \cdot \mathrm{s}^{-1}\right)$, and Kurieka $\left(700 \mathrm{~m}^{3} \cdot \mathrm{s}^{-1}\right)[2]$, join its right-bank zone and constitute about $80 \%$ of the basin area [3]. Artificial radionuclides have been released into the Yenisei River since 1958 by the operation of the Mining and Chemical Combine (MCC). This complex involved three special type nuclear reactors (two direct-flow and one with a closed cooling cycle) which produced weapon grade plutonium, a radiochemical plant for irradiated fuel reprocessing and a storage of resultant radioactive wastes [4]. The MCC is located on the eastern bank of the Yenisei River, about $60 \mathrm{~km}$ downstream the city of Krasnoyarsk, and radioactive substances were directly dumped into the river at several points downstream this area. Throughout this period, the environmental monitoring has been periodically performed by the Hydrometeorological Service and other bodies $[2,5,6]$. Following the shutdown of two direct-flow reactors in 1992 there was a considerable reduction of the discharge of radioactive substances [3, 4]; however, the total level of radioactive contamination of floodplain soils and riverine sediments decreased mainly due to the physical decay of short-lived radionuclides [5, 7-13]. At present, cooling water from the third still running nuclear reactor as well as drain waters from the reactor and the radiochemical reprocessing is discharged into the river after an intermediate storage in a holding basin.

The objectives of this work were (i) to study the contemporary chemical-radiation situation of the middle reach of the River Yenisei (ii) to analyze with mathematical calculations the migration processes which led to the measured activity concentrations along the river and within the sediments. 


\section{Objects and Methods}

\subsection{Sampling Technique}

Water samples were taken every month in summer-autumn at low-water during several years. The samples were taken in the upper layer of the stream $(0-10 \mathrm{~cm})$ into plastic bottles of $25 \mathrm{~L}$. The samples to be studied were taken along the right bank at a distance of 40-60 m from the edge of the river bank. Controls were taken at a distance of $500 \mathrm{~m}$ from the edge of the left bank, on the main waterway characterized by the highest current speed and the biggest depth. If the year of sampling is mentioned, it would be better.

\section{$2.2 \quad$ Ultra-filtration of Suspensions}

Just after sampling $1 \mathrm{~L}$ of the sample was ultra-filtered successively through acetate-cellulose membrane filters called Millipore (with a diameter of $47 \mathrm{~mm}$ ) having the pore size being 5, 1, 0.45 and $0.2 \mu \mathrm{m}$ to separate suspensions and fractionate them according to the pore size. The precipitates on the filters were dried till air-dried state and the morphology and particle composition were studied with an electron microscope. The precipitate was also studied to determine gross elemental composition by size fractions.

\section{$2.3 \quad$ Methods}

The electron microscopy investigations were carried out using a scanning electron microscope TM- 1000 (Hitachi, Japan) with the X-ray spectral energy-dispersive analyzer SwiftED (Oxford Instrument Analytical, England) recorded with backscattered electrons, with the accelerating voltage being $15 \mathrm{kV}$ in the low vacuum regime.

The investigations were carried out without the preliminary deposition of the conductive coatings upon the samples. The suspended matter extracted by ultrafiltration directly on the filters was fixed on the work table with double-sided conductive carbon tape and placed into the chamber of the electron microscope. The electron backscattering micrographs were scanned, captured as a separate file and subjected to the standard digital processing to increase the image sharpness and contrast. Some parts of the samples (selected particles, characteristic features) were subjected to spectral analysis.

The investigations were carried out using a scanning electron microscope JEOL JSM-7001F with the X-ray spectral energy-dispersive analyzer Oxford Instrument INCA PentaFETx3. Here, the filters were covered with a sputter-deposited gold layer with the thickness equal to $15 \mathrm{~nm}$. The Au layer was made in high vacuum using JEOL JEE 420.

\subsection{Mathematical Calculations of the Mass Transport of Technogenic Radionuclides}

The model of radionuclide transport along the Yenisei River is based on a modified one-dimensional model proposed by Schnoor et al. [14]. For the whole length of the Yenisei, a homogeneous distribution of radionuclides over the cross section is presupposed. It is assumed that both in the water column and in the active sediment layer the radionuclides are present in two forms: soluble and adsorbed on particles. The most important processes influencing the behavior of radionuclides include adsorption and desorption, sedimentation of suspended particles from the river water and resuspension from the active sediment layer, activity exchange between the pore water of the sediment and overlying water due to diffusion through the boundary, and radioactive decay.

The calculations presented in the given paper are limited to the abiotic form of substance transport since the contribution of the biogenic component is considered to be insignificant [15].

Complex fresh water systems, such as large rivers, are assumed to be composed of a chain of interconnected "elementary segments (ES)" that are comprised of: a) the water column; b) an upper sediment layer strongly interacting with water ("interface layer"); c) an intermediate sediment layer below the "interface layer" ("bottom sediment"); d) a sink sediment layer below the "bottom sediment"; e) the right and left sub-catchments of each ES.

Depending on the water discharge rate and geometry of the river bed the stream velocity varies which determines the transport of the sediment suspensions and sediment disturbance-sedimentation. To 
estimate the accumulation of radionuclides in the bottom sediments a mathematical model described in paper Belolipetsky and Genova was used [16].

The concentrations of radionuclides on solid particles were assumed to be proportional to the area of the particle surface using the field data of the fraction distribution of radionuclides in the initial solution. Then, the particle transport and sedimentation along the river bed was estimated. In the channels and floodplain (in the areas with small stream velocities) there occurs sedimentation of the sediment suspensions. During the periods of the increased water discharge rate (spring floods, increased volume of the hydroelectric station), the sediment disturbance is also possible as well as transport of impurities downstream (secondary pollution).

To describe the sediment suspension transport in a turbulent flow of non-compressible liquid a simplified equation is used:

$$
\partial S_{i} / \partial t+u_{B} \partial S_{i} / \partial x=q_{S i} / h+q / \omega \cdot S_{i q}
$$

where $S_{i}$ is the concentration of the $i$-th fraction $\left[\mathrm{kq} \cdot \mathrm{m}^{-3}\right] ; S_{i q}$ is the concentration of an impurity of the $i$-th fraction, entering with the tributary on the way $q ; q_{S i}$ is sediment disturbance-sedimentation of the impurity of the $i$-th fraction; $t$-time; $x$-is a coordinate directed along the current; $Q$ is the discharge rate; $\omega$ - is the cross section area of the river bed; $u_{B}=Q / \omega$ is the cross-section average velocity $h$ is the depth.

The bottom exchange is determined by the formula

$$
\begin{gathered}
q_{S i}=\left(S_{i t r}-S_{i 0}\right) \cdot \omega_{g i}, S_{i t r}=0.01 \cdot \alpha_{i} \cdot S_{t r}, q_{S}=\sum q_{S j} \\
S_{t r}= \begin{cases}0.2 \cdot u_{B} / g h \omega_{g}, \text { if } w_{g}<\omega_{*} \\
\omega_{g}=\left(\rho_{S}-\rho_{B}\right) / \rho_{B} \cdot g / 1 \cdot 8 v \cdot d_{c p}^{2} \\
0, \quad \text { if } \omega_{g} \geq \omega_{*}\end{cases}
\end{gathered}
$$

The transport capability of the flow $S_{t r}$ depends on the depth-average flow velocity, depth and hydraulic coarseness; $q_{S}$ is the mass exchange with the bottom.; $S_{i 0}$ - is the concentration of the $i$-th fraction near the bottom; $\alpha_{i}$ - is the percent content of the $i$-th fractions in the bottom sediments. When calculating $S_{i}$ tr using equation (3) it should be taken into account that $S_{i}$ tr cannot exceed the concentration of the $i$-th fraction in the bottom sediments $\left(S_{i d a y}\right)$, therefore, when $S_{i \text { tr }}>\mathrm{S}_{i \text { day }}$ it is assumed that $S_{i t r}=S_{i d a y}$. If the concentration of the $i$-th fraction in the bottom sediments is equal to zero, then $S_{i t r}=0$.

The main change in the bottom sediment composition is assumed to be due to sediment disturbance and sedimentation. When $q_{s}>0$, the bottom sediments enter the flow (washing out, sediment disturbance), and when $q_{s}<0$ the silting of the river bed is observed (sedimentation of the suspended particles).

Let $z *$ be the thickness of the active layer of the bottom sediments. Assuming that the formation of the upper layer of the bottom sediments (with the thickness $z^{*}$ ) results from the sediment disturbancesedimentation, the mass conservation equation for the $i$-th fraction in the bottom sediments $S_{i \text { day }}$ is written as follows:

$$
\partial\left(z_{*} \cdot S_{i d a y}\right) / \partial t=-q_{S i}
$$

Since $\sum q_{S i}=q_{S}, \sum S_{i \text { day }}=\rho$, from equation (4) one obtains the equation to find $z_{*}$ : $\partial z_{*} / \partial t=-q_{S} / \rho$

The calculation algorithm for the suspended and bottom sediment dynamics consists of the following stages:

Stage 1. The water flow rates $u_{B}$ are determined as well as the depth $h$ from the solution of the SaintVenant equation.

Stage 2. Determination of the initial conditions. The granulometric composition of the bottom sediments in the section $x=x_{j}$ is taken to be $\left(d_{\mathrm{i}}, a^{0}{ }_{i d a y, j}\right)$, where $d_{i}$ - is the diameter of the $i$-th fraction particle $(\mathrm{mm}), a_{i d a y, j}^{0}$ - is the percentage of the $i$-th fraction in the bottom sediments, $i=1,2, \ldots, n$.

Stage 3. Establishment of the boundary condition in the initial section $\left(x=x_{0}\right)$. In the initial section $S^{n}$ iday, 0 are determined using relations employed for the second stage, $S^{n}{ }_{i, 0}$ are estimated using the field data. 
Stage 4. Estimation of the mass-exchange between the bottom and water flow. From the condition wgi $\leqslant \mathrm{w}^{*}, \mathrm{w}^{*}=0.4 \mathrm{u}^{*}$ one determines the fractions which are suspended. Let the suspended fractions be assigned the following index $i=1,2, \ldots i^{*}$, ai,j - is the percentage of the suspended fractions in the section. The percentage of all the suspended fractions is $r j=a 1$, day,j $+a 2, d a y, j+\ldots+$ ai,day,j. Then, the percentage of the suspended $\mathrm{i}$-th fraction is $\mathrm{ai}, \mathrm{j}=100 \mathrm{rj}-1$ ai,day, $\mathrm{j}, \mathrm{i}=1,2, \ldots \mathrm{i}$. If $\mathrm{rj}=0$ (the suspended fractions are absent), then, all $a \mathrm{i}, \mathrm{j}=0$..

Stage 5. Estimation of the concentrations of the suspended and bottom sediments as well as the location of the water-bottom interface.

Stage 6. Calculation of the granulometric composition of the bottom sediment: ai, д н, $\mathrm{j}=\mathrm{Sn}+1 \rho-$ 1100 .

Stage 7. Estimation of the bottom sediment radioactive contamination in the calculation sections.

Each fraction is assumed to be uniformly contaminated by radionuclides: Rni,j= $\lambda \mathrm{iSni,j}$. Knowing the contamination level in the initial section Rni, $0=\lambda$ iSni, 0 , it is possible to estimate the level of the radionuclide contamination in the sections downstream the river Rni,j $=$ Sni,j (Soi,j)-1 Rni,0 .

In the next time interval the calculations are repeated (from stage 3 to stage 7 ).

\section{$3 \quad$ Results and Discussion}

The investigations were carried out in the middle reach of the River Yenisei at the site $15 \mathrm{~km}$ (from the inflow of the Ploskii stream $(0 \mathrm{~km})$ to the village Bolshoy Balchug $(15 \mathrm{~km})$ (Figure.1). At the water discharge $\mathrm{Q}=4085 \mathrm{~m}^{3} / \mathrm{s}$ at the given site the depth of the river and current speed are determined to be $H \approx 7 \mathrm{~m}, v=1.25-1.8 \mathrm{~m} / \mathrm{s}$, respectively. The stream with technogenic admixtures propagates along the right bank of the river not more than 0.1 one-tenth of the width of the river, i.e. along the flood plain where the river flow speed and the width are several times less.

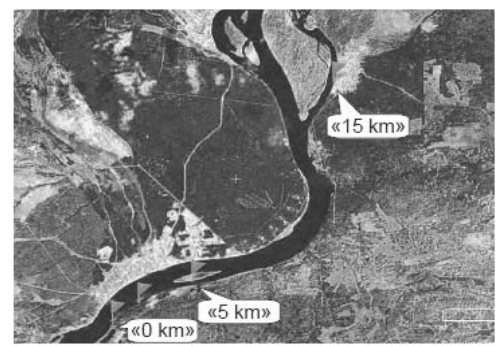

Figure.1. Review scheme of the study area. Sampling points: "0 km"- 56027'05”N, 93036'31'"E; " 2 km"- 56 23 '18"N,

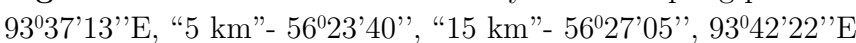

\subsection{Material Composition of the Water Suspensions}

As a result of ultra-filtration, it was found that the main part of the suspended particles (up to $90 \%$ ) was concentrated in the pelitic fraction of $>5 \mu \mathrm{m}$. The filters with the suspensions were fixed on the specimen mount with the help of the conducting double-sided adhesive carbon type and placed into the electron microscope chamber. The precipitate was found to contain particles of quartz, mica and ironcontaining minerals (limonitic and magnetic iron), mainly, with the size not exceeding 10-15 $\mu \mathrm{m}$. Also, the precipitate revealed the presence of a considerable amount of various biological objects (diatoms, annelids, plant spores, etc.). All the mineral particles and biota were covered with a layer of fine limonitic-clayish particles. Spectral analysis of some parts of the sample (selected particles, characteristic details) was carried out. The suspended matter contains a large colony of diatoms, for example, Meridian circulare, some cyclotellas and opyphoros, Cyclotella vor. Jacutca (Figure.2). 

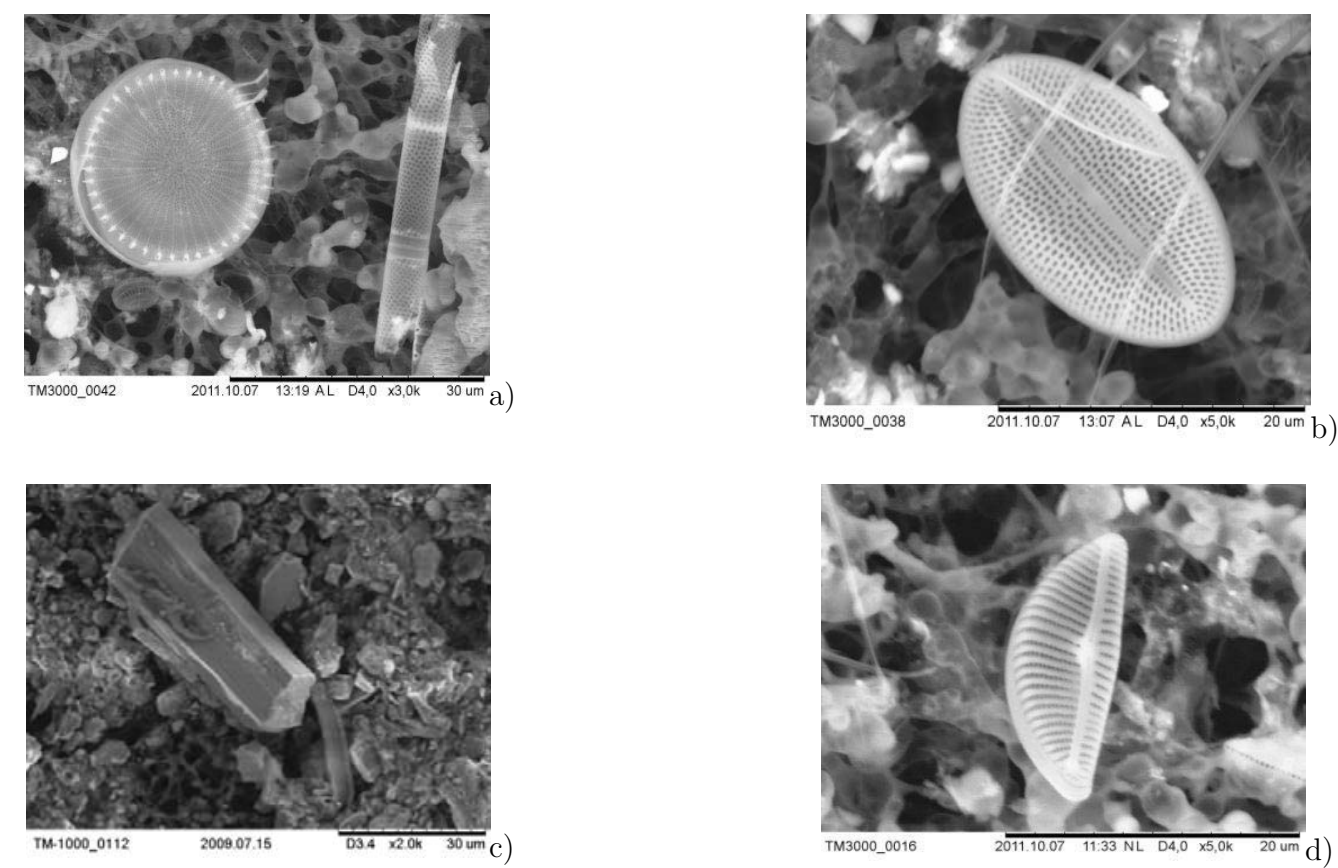

Figure. 2. Material composition of the water suspensions (separated by the ultra-filtration method). The fraction $\geqslant 5 \mu \mathrm{m}$. Magnification power of $\mathrm{x} 2000$.

The fraction with the size of " $5-1 \mu m$ " uniformly covers the filter surface with a layer of fine particles. The brown-colour precipitate consists mainly of mineral components (calcite, clays, clayish minerals, quartz and gypsum debris) (Figure. 3).
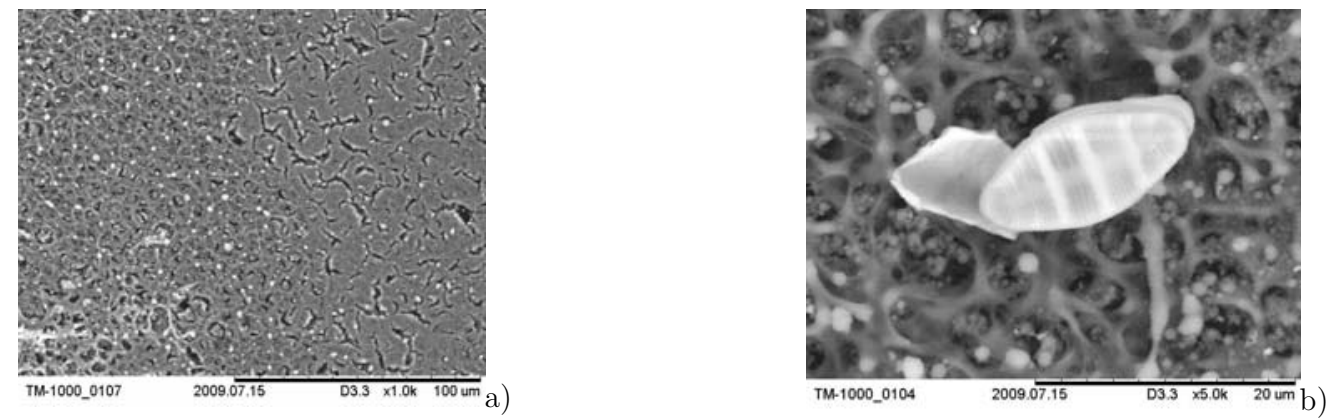

Figure. 3. Material composition of the water suspensions (separated by the ultra-filtration method). The fraction $\geqslant 1 \mu m$. Magnification power of x1000 (a), x2000 (b).

The fraction "1.0-0.2 $\mu \mathrm{m}$ " uniformly covers the filter surface with a layer of fine particles of the micron and submicron size, they are mainly aluminosilicate compounds having various structure and composition, limonite, calcite and gypsum (Figure. 4). 

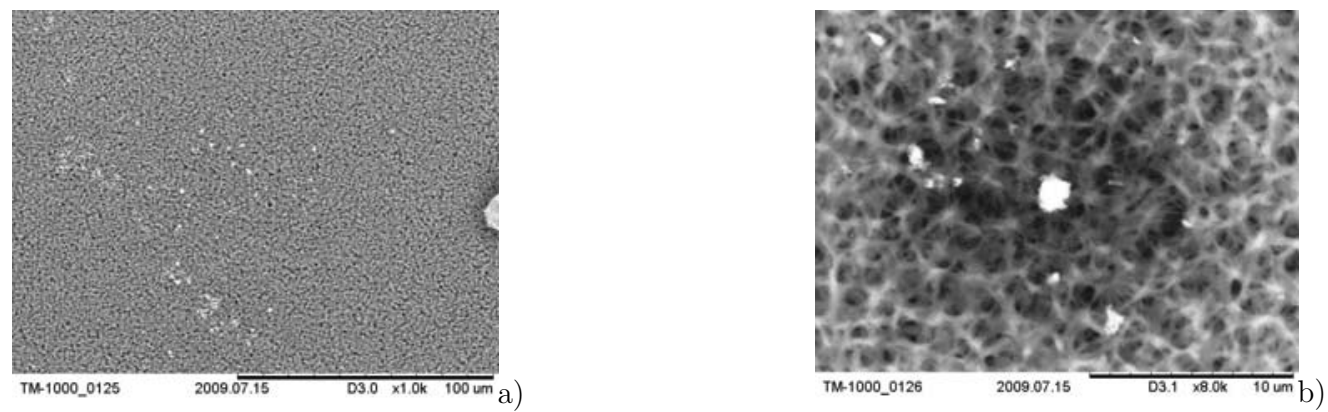

Figure. 4. Material composition of the water suspensions (separated by the ultra-filtration method). The fraction $\geqslant 0.2 \mu \mathrm{m}$. Magnification power of x1000 (a), x2000 (b).

Figure. 5 Presents a fragment of the filter and the suspended sediment water sample taken in the Yenisei River. The distribution map of the elemental composition and the content of the main elements in atom percent are also presented.
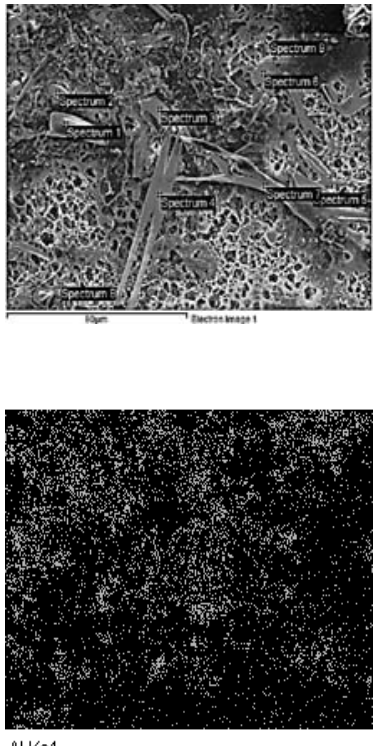

Al Ka1

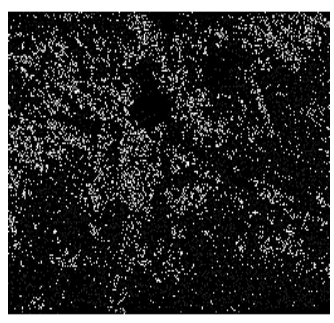

OKa1

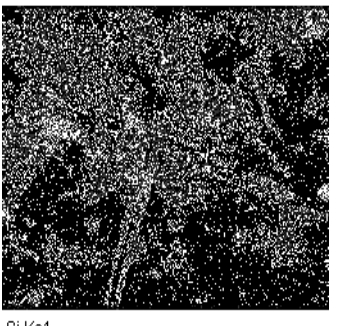

SiKa1

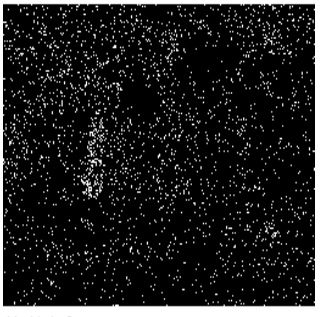

Mg Ka1_2

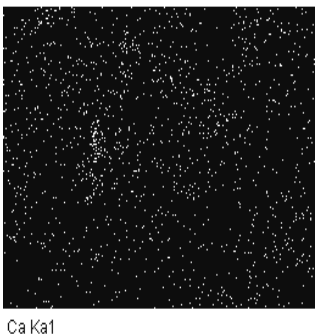

CaKa1

\begin{tabular}{l|c|c|c|c|c|c|c|c}
\hline \multirow{2}{*}{ Spectrum } & \multicolumn{7}{|c}{ Atomic \% } \\
\cline { 2 - 10 } & $\mathrm{C}$ & $\mathrm{O}$ & $\mathrm{Mg}$ & $\mathrm{Al}$ & $\mathrm{Si}$ & $\mathrm{K}$ & $\mathrm{Ca}$ & $\mathrm{Fe}$ \\
\hline Spectrum 1 & 11.18 & 61.23 & - & - & 27.59 & - & - & - \\
\hline Spectrum 2 & 16.91 & 65.74 & - & 0.49 & 16.87 & - & - & - \\
\hline Spectrum 3 & 45.79 & 24.18 & - & 0.89 & 29.15 & - & - & - \\
\hline Spectrum 4 & 44.91 & 44.21 & - & 0.60 & 10.28 & - & - & - \\
\hline Spectrum 5 & 38.34 & 48.75 & - & 0.62 & 12,29 & - & - & - \\
\hline Spectrum 6 & 67.14 & 29.54 & - & - & 3.32 & - & - & - \\
\hline Spectrum 7 & 73.45 & 24.45 & - & 0.48 & 1.62 & - & - & - \\
\hline Spectrum 8 & 63.42 & 30,19 & - & 2.31 & 3.76 & 0.33 & - & - \\
\hline Spectrum 9 & 17.12 & 55.72 & 2.99 & 6.10 & 12.46 & 0.42 & - & 5.19 \\
\hline Sum Spectrum & 63.00 & 30.56 & 0.28 & 1.12 & 3.77 & 0.19 & 0.22 & 0.86 \\
\hline
\end{tabular}

Figure. 5. Layout and elemental composition of the suspended matter fragment of the Yenisei River. The fraction $\geqslant 1 \mu \mathrm{m}$. Magnification power $\times 750$. 
Fig. 6 shows the fragments of the filter with the suspended substance obtained from the water sample taken in the mouth of one of the discharge channels of MCC. For each fragment the elemental composition in atom percent is presented.

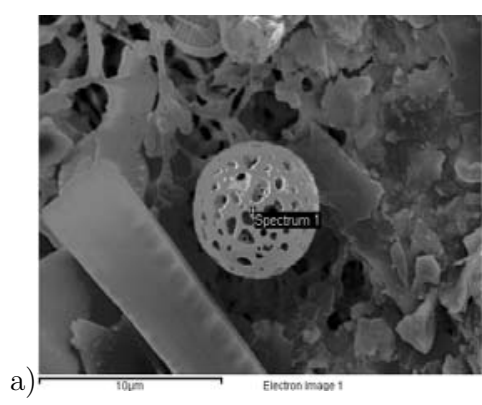

\begin{tabular}{cccccc}
\hline \multicolumn{7}{c}{ Atomic \% } \\
\hline $\mathrm{C}$ & $\mathrm{O}$ & $\mathrm{Al}$ & $\mathrm{Si}$ & $\mathrm{Ca}$ & $\mathrm{Fe}$ \\
\hline 35.1 & 42.2 & 1.2 & 2.2 & 1.0 & 18.3 \\
\hline
\end{tabular}

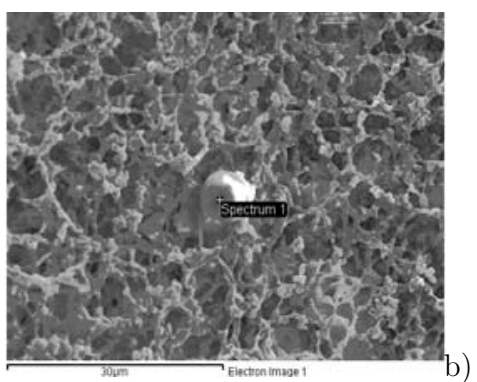

\begin{tabular}{ccccc}
\hline \multicolumn{5}{c}{ Atomic \% } \\
\hline $\mathrm{C}$ & $\mathrm{O}$ & $\mathrm{Mg}$ & $\mathrm{Al}$ & $\mathrm{Si}$ \\
\hline 6.5 & 71.8 & 0.7 & 10.8 & 10.8 \\
\hline
\end{tabular}

Figure. 6. Fragments of the suspended matter sample from the water taken in the MCC discharge area (including the elemental analysis). The fraction $\geqslant 1 \mu \mathrm{m}$. Magnification power $\times 5000(\mathrm{a}), \times 2000(\mathrm{~b})$.

Figure. 7 presents an X-ray pattern of a silicate microsphere with the diameter of about 1-15 $\mu \mathrm{m}$ which can result from the operation of thermal power plants or coal boiler stations since the particles of such morphology and composition are characteristic for coal
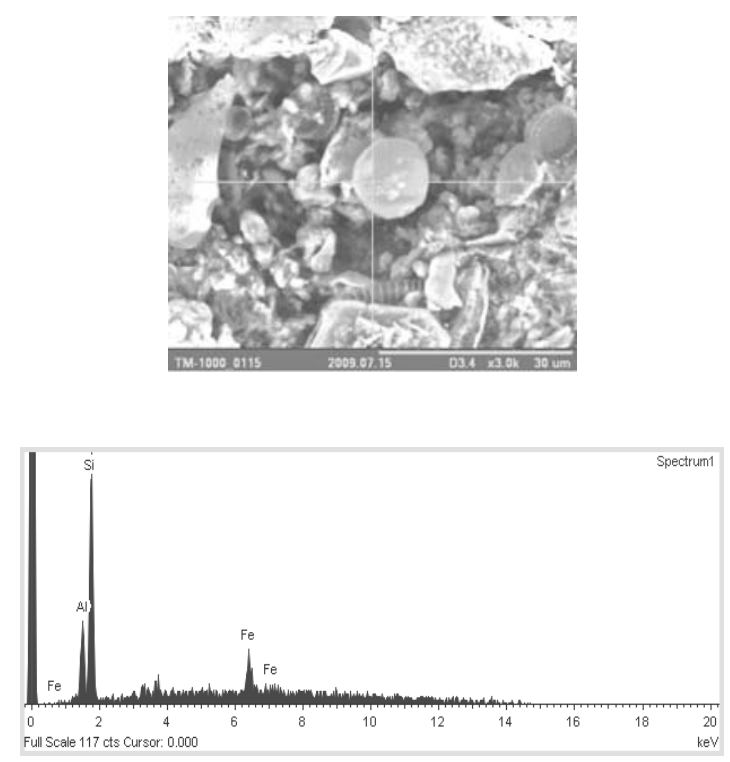

Figure. 7. Energy dispersive X-ray spectrum. The fraction $\geqslant 5 \mu \mathrm{m}$. Magnification $\times 10000$

The material composition of the solid suspensions in the Yenisei River water generally corresponds to the mineral compositions of the rocks and the products of their hypergenesis which form the channel and the banks of the river. Occasionally, the admixture of the particles of technogenic origin (ash wastes from boiler stations) is observed.

Thus, it was shown that the suspended substance is similar in its geomorphology with the bottom sediments of the Yenisei River. However, the suspensions entering the river with the industrial discharge water significantly differ from the suspensions of the mainstream both in their composition and particle size. 
At the sampling of the district runoff of radionuclides when the time of the discharge contact with the river water was insignificant, the radionuclides ${ }^{3} \mathrm{H},{ }^{24} \mathrm{Na},{ }^{60} \mathrm{Co},{ }^{239} \mathrm{~Np}$ and ${ }^{99} \mathrm{Mo}(\sim 90 \%)$ were mainly presented as a fraction $<0.2 \mu \mathrm{m}$ (filtrate). These can be both free ions in the molecular solution (e.g., ${ }^{24} \mathrm{Na}^{+}$), and molecules or sorbed ions in colloid particles which managed to pass through a $0.2 \mu \mathrm{m}$ filter. The solid phase is mainly presented by ${ }^{46} \mathrm{Sc},{ }^{214} \mathrm{Bi},{ }^{103} \mathrm{Ru}$, with the last two isotopes being in the most coarse fraction (more than $90 \%$ of them). ${ }^{85} \mathrm{Sr}$ and ${ }^{131} \mathrm{I}$ have less uniform phase distribution. ${ }^{76} \mathrm{As}$ is almost absent in the most coarse fraction $(>5 \mu \mathrm{m})$. In the samples taken $5 \mathrm{~km}$ downstream there is a decrease of the total activity, first of all, due to the coarse particle sedimentation. The radionuclide redistribution according to the size fractions was found: almost the whole amount of ${ }^{60} \mathrm{Co}$ is concentrated in the fraction with the size of $>1 \mu \mathrm{m}$, a considerable amount of ${ }^{214} \mathrm{Bi}$ is transformed into a solution (the fraction $<0.2 \mu \mathrm{m}$ ), almost $40 \%$ of ${ }^{99} \mathrm{Mo}$ and up to $70 \%$ of ${ }^{24} \mathrm{Na}$ are transformed into the fraction of 1-0.2 $\mathrm{mm}$. With the total background level decrease there appear natural radionuclides ${ }^{212} \mathrm{~Pb}$ and ${ }^{234} \mathrm{Th}$ in the solid phase as well as ${ }^{65} \mathrm{Zn}$ in the solution.

\subsection{Mathematical Calculations of the Mass Transport of Artificial Radionuclides in the Water Flow}

Calculations have been made according to the described method in the area of the River Yenisei from the estuary of the river Ploskii up to the island Atamanovskii. Assuming the water discharge to be $Q=4085 \mathrm{~m}^{3} / \mathrm{s}$ the river depth $H \approx 7 \mathrm{~m}$ and the flow rate $v=1.25 \div 1.8 \mathrm{~m} / \mathrm{s}$ in the given section are estimated based on the hydraulic model. According to an earlier estimate, the stream with the technogenic admixtures propagates along the right bank not far than one tenth of the river width, i.e. along the flood plain where the flow rate and depth are several times lower than those calculated based on the hydraulic model. According to the calculations made: $H_{\Pi} \approx 2.5 \mathrm{~m}, v_{\Pi} \approx 0.38 \div 0.44 \mathrm{~m} / \mathrm{s}$.

The influence of the suspension-sedimentation processes on the admixture transport in the river flow close to the right bank of the River Yenisei in the studied area has been estimated.

The calculations made show that the concentrations of the lightest fraction in the calculation area almost do not change, while for the heavier fractions the decline of the suspended sediment concentrations is observed and the level of the radionuclide contamination also decreases (Table 1).

Table 1. Concentrations of particulate matter size fractions: real and calculated data

\begin{tabular}{|c|c|c|c|c|}
\hline$d, \mathbf{M м}$ & 0.00020 & 0.00045 & 0.005 & 0.01 \\
\hline \multicolumn{5}{|c|}{ District reset $\mathrm{MCC}$} \\
\hline$S^{0}$, г/л & 0.0001 & 0.0005 & 0.0043 & 0.0031 \\
\hline$R^{0}, \mathrm{БК} / \kappa \Gamma$ & 118.904 & 0.1728 & 0.1165 & 1.8224 \\
\hline \multicolumn{5}{|c|}{ island Atamanovsky } \\
\hline$S_{\text {_nnat }}$ & 0 & 0.0001 & 0.0009 & 0.0583 \\
\hline S_calc & 0.0001 & 0.0005 & 0.0039 & 0.0021 \\
\hline \multicolumn{5}{|c|}{ island Atamanovsky } \\
\hline$R \_n a t$ & 2.4727 & 0.01101 & 0.01596 & 0.0853 \\
\hline$R \_$calc & 118.9009 & 0.1727 & 0.1044 & 1.2065 \\
\hline
\end{tabular}

In the field data the increase of the coarse fraction concentration is observed which is not connected with the suspension-sedimentation process. ( $S \_$nat, $R \_$nat are the measured values, $S \_$calc, $R \_$calc are the calculated ones).

Thus, the abiogenic mass-transport of the technogenic radionuclides, metals being among them, occurs mainly due to the coagulation of the suspended particles and contamination redistribution into bigger fragments.

Our calculations show that the concentration of the lightest fraction of the water on the current site remains virtually unchanged. However, we observed that concentrations of suspended sediment decreases for heavier fractions decrease and, consequently, decreased the level of contamination. In addition, our field data indicated an increase in the concentration of coarse fraction, which is associated not only with the resuspension-deposition, as well as with the coagulation of suspended solids. 
Thus, long-term monitoring confirms the data on artificial radionuclides entering the Yenisei River water which is likely to be connected with the activity profile of the industrial enterprises located on the banks of the studied area of the river bed.

Acknowledgments. We thank the Russian Fundamental Bureau for the Investigations N-16-05-00205.

\section{References}

1. C. Revenda, S. Murray, J. Abramovitz, A. Hammond, "Watersheds of the World: Ecological value and vulnerability". Word Resources Institute and vulnerability, Washington DC, USA, 1998.

2. L. Bondareva, "New data on the radioecological state of the River Yenisei", Russian chemical journal Mendeleev's community, no. 3, pp.153-161 (in rissain).

3. S.M. Vakulovasky, I.I. Kryshev, A.I. Nikitin, Yu.V. Malyshev, E.G. Tertyshnik, "Radioactive contamination of the Yenisei River", Journal of Environmental Radioactivity, no. 29, pp. 225-236, 1995.

4. Vakulovsky, S.M. "Estimation and prediction of the consequences for the environment and population of radioactive contamination of the River Yenisei by discharges of the Krasnoyarsk Mining and Chemical Industrial Complex". Final Project Technical Report of International Science and Technology Centre (ISTC) Project 1404. SPA-Typhoon, Obninsk, Russia, 2003.

5. A.V. Nosov, M.V. Ashanin, A.B. Ivanov, A.M. Martynova, "Radioactive contamination of the River Yenisei due to discharges from the Krasnoyarsk Mining and Chemical Corporation", Atomic Energy, vol. 74, pp. 139-144, 1993.

6. L. Bondareva, "The relationship of mineral and geochemical composition to artificial radionuclide partitioning in Yenisei River sediments downstream from Krasnoyarsk", Environmental Monitoring and Assessment, no. 6, pp. 3831-3847, 2012.

7. Nosov, A.V. 1996. Analysis of the radiation environment on the Yenisei River after decommissioning of straightthrough reactors at the Krasnoyarsk Mining-Chemical Complex. Atomic Energy, 81: 670-674.

8. L. Bondareva, A. Zhizhaev, "Radiation-chemical situation of the waters of the middle reach of the River Yenisei (Russian Federation)", Journal of Environmental Science and Engineering, vol. 9, pp. 1-11, 2010.

9. T. Semizhon, S. Röllin, Y. Spasova, E. Klemt, "Transport and distribution of artificial gamma-emitting radionuclides in the River Yenisei and its sediment", Journal of the Environmental Radioactivity, vol.101, no. 5, pp. 385-402, 2010.

10.A. Bolsunovsky, L. Bondareva, "Actinides and other radionuclides in sediments and submerged plants of the Yenisei River", Journal of Alloys and Compounds, no. 444-445, pp. 495-499, 2007.

11.S.M. Vakulovsky "Radioactive contamination of surface water on the territory of Russia in 1961-2008 years", In Problems of hydrometeorology and environmental monitoring. Obninsk, vol. 2, pp. 115-127, 2010. (in russian).

12.Y. Kuznetsov, Y.U. Revenko, V.K. Legin "The assessment of the contribution of the Yenisei River in the total radioactive Contamination of the Kara Sea", Radiochemistry, no. 6, pp. 546-553, 1994.

13.Y. Kuznetsov, V.K. Legien, A.E. Shishlov, "The behavior of 239, 240Pu and 137Cs in the Yenisei River - the Kara Sea", Radiochemistry, no. 2, pp. 181-186, 1999.

14.J.L. Schnoor, D.J. Mossmann, V.A. Borzilov, M.A. Novitsky, "Mathematical model for chemical spills and distributed source runoff to large rivers". In Fate of Pesticides and Chemicals in the Environment. Wiley Interscience, New York, Environmental Science and Technology Series, 1992, pp. 347-370.

15.F.V. Sukhorukov, A.G. Degermendzhy, V.M. Belolipetsky, Patterns of distribution and migration of radionuclides in the valley of the Yenisei River. Novosibirsk: Russian Academy of Sciences, a subsidiary of "Geo", 2004. (in russian).

16.V.M. Belolipetsky, S.N. Genova, "Calculating algorithm for definition of dynamics of suspended and bed sediments in channel", Computational technologies, no. 2, pp. 9-25, 2004. (in russian) 